\title{
FUSION OF TYPICAL THORACIC VERTEBRAE
}

\section{Nivedha Viswanathan*1, Ayesha Parveen ${ }^{2}$, Yuvaraj Maria Francis ${ }^{3}$, Priya Dharshini gowthaman. A 4 .}

${ }^{* 1,2}$ BPT Student, Saveetha College of Physiotherapy, Saveetha Univeristy, Chennai, Tamilnadu, India.

3,4 Tutor, Department of Anatomy, Saveetha Medical College, Saveetha Univeristy, Chennai, Tamilnadu, India.

\section{ABSTRACT}

Any abnormal fusion of vertebrae results in a clinical condition called block vertebrae or vertebral synostosis. Among all the known vertebral fusion, the fusion of thoracic vertebrae is less common and comparatively rare. During the formation of vertebral column in the $4^{\text {th }}$ week of intrauterine life the sclerotome part of the somites migrate around the notochord and the neural tube and undergoes a process called resegmentation. Any defect in such a process can lead to vertebral anomalies causing neurological signs and symptoms. The possible cause for the fusion of thoracic vertebra can be congential, vertebral malformations DISH (diffuse idiopathic skeletal hyperostosis) and other rheumatological degenerative diseases or infections like tuberculosis. This can lead to wide complications affecting different systems of the body. The fusion of thoracic vertebra can present many clinical signs including formation of abnormal curvatures of the spine like scolosis, kyphosisetc the objective of the study is to present a case on the fusion of typical thoracic vertebra.

KEY WORDS: Vertebral Malformations, Block Vertebrae, Scoliosis, Kyphosis, Sclerotome.

Address for Correspondence: Ms. Nivedha Viswanathan, No.39, Ashok Brindavan Nagar, 1st main road, Iyyappanthangal, Chennai-600056, Tamilnadu, India. E-M ail: v.nivedha2008@ gmail.com

\begin{tabular}{|c|c|c|}
\hline \multicolumn{3}{|c|}{ Access this Article online } \\
\hline \multirow{3}{*}{$\begin{array}{c}\text { Quick Response code } \\
\text { Dol: } 10.16965 / \text { ijar.2017.219 }\end{array}$} & \multicolumn{2}{|c|}{$\begin{array}{c}\text { Web site: International Journal of Anatomy and Research } \\
\text { ISSN 2321-4287 } \\
\text { www.ijmhr.org/ijar.htm }\end{array}$} \\
\hline & $\begin{array}{l}\text { Received: } 12 \text { Apr } 2017 \\
\text { Peer Review: } 12 \text { Apr } 2017\end{array}$ & $\begin{array}{l}\text { Accepted: } 23 \text { M ay } 2017 \\
\text { Published (0): } 30 \text { Jun } 2017\end{array}$ \\
\hline & Revised: None & Published (P): 30 Jun 2017 \\
\hline
\end{tabular}

\section{INTRODUCTION}

A typical vertebra consists of a vertebral arch and foramen, a body, transverse processes and usually a spinous process. Thoracic vertebra compose the middle segment of the vertebral column, between the cervical and lumbar vertebrae. In humans there are 12 thoracic vertebrae with the expections of $\mathrm{T} 1, \mathrm{~T} 9, \mathrm{~T} 10, \mathrm{~T} 11$ and $\mathrm{T} 12$ are called typical thoracic vertebrae. The Vertebrae develops from the sclerotome portions of the somites, which are derived from paraxial mesoderm.As development proceeds the sclerotome portions of each somite undergoes a process called resegmentation. Resegmentation occurs when the caudal half of each sclerotome grows and fuses with cephalic half of each sub adjavent sclerotome. Thus each vertebrae is formed fromthe combination of the caudal half of one somite and the cranial half of its neighbour. M esenchymal cells between cephalic and caudal parts of the original sclerotome segment do not proliferate but fill the space between two precartilagenous vertebral bodies. In this way they contribute to the formation of invertebral discs.

Congenital anamolies are common in the vertebral column, awareness of vertebral anomalies are useful to anastomosis and to clinicians as 
these anomalies may be result in pain, decreased mobility, muscular weakness of limbs and sensory deficits $[1,2]$. It has got value for physiciancs, surgeons, radiologists, orthopaediciancs, anesthetics, rheumatologists, pathologists, paediatricians and for forensic medicine also. Various vertebral anomalies of anatomic interest have been reported viz, occipitalisation, sacralisation; lumbarisation absence of posterior elements of vertebral arch and vertebral synostosis. fusion of vertebra at single or multiple levels is reffered to as block veretebra or vertebral synostosis or spinal fusion [3]. The fusion of 2 or more vertebrae can be congenital or acquired. the fusion may be congential due to failure of segmentation of sclerotomes at certain levels at the time of organogenesis, leading to klippelfeil syndrome or other associated spinal deformities such as scolosis [3]. The acquired fusion of vertebrae is secondary to trauma, tuberculosis or other infections and juvenile, rheumatoid arthritis [1]. Congenital fusion of vertebrae most commonly involves cervical regions $[4,5]$. The surgical fusion of 2 vertebrae is known as spondylodesis or spondylosyndesis fusion of thoracic vertebrae can present clinical signs like, congentials- colosis, shortening of trunk with scoliosis or lordosis in older children [6]. The spinal fusion may cause restricted movements, premature degenerative changes and associated neurological deficits $[5,7]$. The symptoms may vary according to the extent and level of vertebral fusion.

\section{CASE REPORT}

While teaching the students, during normal classes we adminstred a specimen of fusion between the typical thoracic vertebrae from the Osteology section of Anatomy department of Saveetha M edical College, Thandalam. The features of the fused typical thoracic vertebrae were analysed and the specimen was photographed from anterior, posterior, right lateral, left lateral and superior aspect. The measurements of the fused vertebral specimen were taken with the help of digital vernier calliper. The parameters measured were heights of fused vertebral bodies, diameter and intervertebral foramen.

\section{OBSERVATIONS}

The study details of a fused three typical thora- cic vertebrae. The features and measurements of the fused vertebra are given in Table 1 and shown in Fig. 1-5. The table 2 indicates various measurements of typical fused thoracic vertebrae,

Fusion of three typical thoracic vertebrae: The bodies of typical thoracic vertebrae were partially fused on right side and partially fused on left side. The pedicle, laminae articular processes, and spinous processes were unfused (Fig. 1-5).

Fig. 1: Posterior view of fused vertebrae.

Fig. 2: Anterior view of fused vertebrae.

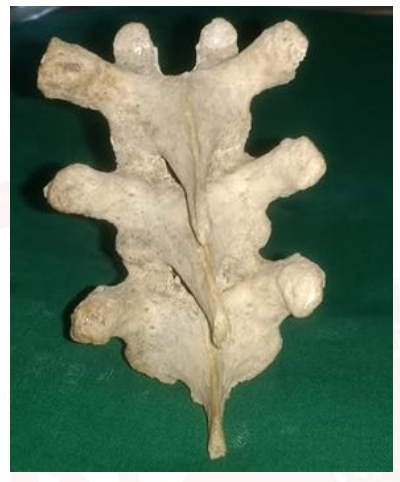

Fig. 3: Left lateral view of fused vertebrae.

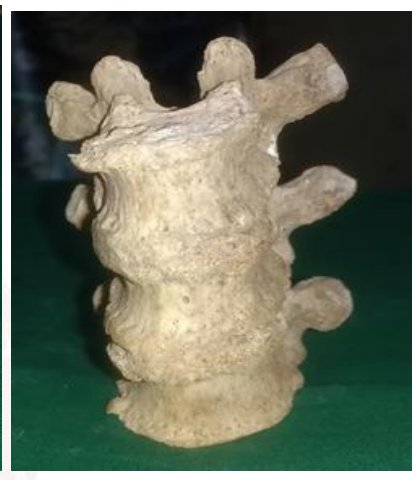

Fig. 4: Right lateral view of fused vertebrae.
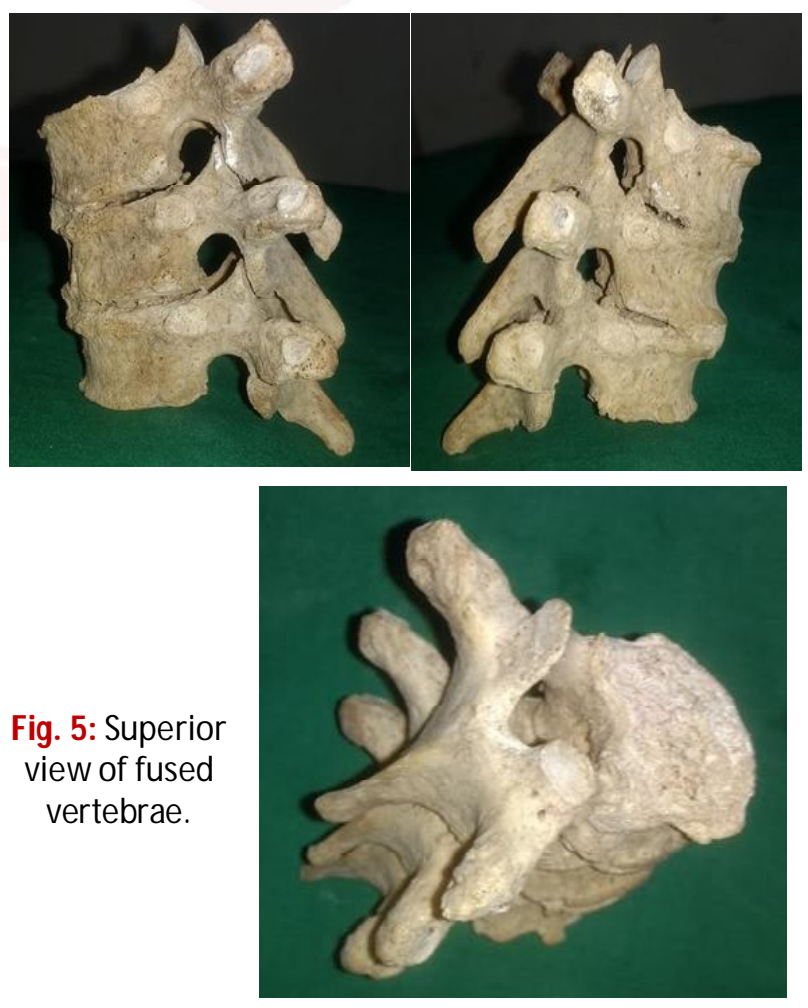

T3-T4 Fusion: The height of fused vertebral bodies was $3.6 \mathrm{~cm}$ on right side and $3.5 \mathrm{~cm}$ on left side. The intervertebral foramen were measured $1.2 \mathrm{~cm}$ on right side and $0.9 \mathrm{~cm}$ on left side (Table 1). 
Table 1: Showing the measurements of fused typical thoracic vertebrae.

\begin{tabular}{|c|c|c|c|}
\hline S.no & Feature & T3-T4 & T4-T5 \\
\hline 1 & $\begin{array}{c}\text { Vertebral bodies Height } \\
\text { [(Right +Left }) / 2]\end{array}$ & $\begin{array}{c}\text { PF- Right side } \\
\text { PF-Left side }\end{array}$ & $\begin{array}{c}\text { PF- Right side } \\
\text { PF- Left side }\end{array}$ \\
\hline 2 & Pedicles & UF & UF \\
\hline 3 & Laminae & UF & UF \\
\hline 4 & Articular processes & UF & UF \\
\hline 5 & Spinous processes & UF & UF \\
\hline 6 & Vertebral foramen & REGULAR & REGULAR \\
\hline 7 & Intervertebral foramen & $\begin{array}{c}\text { Right -Oblique, 1.2; } \\
\text { Left -Arcuate, } 0.9\end{array}$ & $\begin{array}{c}\text { Right-Arcuate, 1.3; } \\
\text { Left -Oblique, 1.0 }\end{array}$ \\
\hline
\end{tabular}

Note: CF: Complete fusion, PF: Partial fusion, UF: Unfused,

T4-T5 Fusion: The height of fused vertebral bodies was $3.9 \mathrm{~cm}$ on right side and $4.1 \mathrm{~cm}$ on left side. The intervertebral foramen measured $1.3 \mathrm{~cm}$ on right side and $1.0 \mathrm{~cm}$ on left side (Tab.2) Table 2: Various parameters of different parts of thoracic vertebrae.

\begin{tabular}{|c|c|c|c|c|}
\hline S.No & \multirow{2}{*}{ Parts of vertebra } & view & $\begin{array}{c}\text { Upper } \\
\text { vertebra }\end{array}$ & $\begin{array}{c}\text { Lower } \\
\text { vertebra }\end{array}$ \\
\hline \multirow{2}{*}{1} & \multirow{2}{*}{ Body } & Antero-posterior & $1.3 \mathrm{~cm}$ & $1.6 \mathrm{~cm}$ \\
\cline { 3 - 5 } & & Transverse & $2.4 \mathrm{~cm}$ & $2.7 \mathrm{~cm}$ \\
\hline \multirow{2}{*}{2} & \multirow{2}{*}{ Spinal canal } & Antero-posterior & $1.4 \mathrm{~cm}$ & $1.5 \mathrm{~cm}$ \\
\cline { 3 - 5 } & & Transverse & $1.9 \mathrm{~cm}$ & $1.8 \mathrm{~cm}$ \\
\hline \multirow{2}{*}{3} & \multirow{2}{*}{ Vertebral for amen } & On right side & \multicolumn{2}{|c|}{0.8} \\
\cline { 3 - 5 } & & On left side & \multicolumn{2}{|c|}{0.8} \\
\hline
\end{tabular}

\section{DISCUSSION}

The vertebral column develops from paired somites, each composed of a dermatome, myotome, and sclerotome. They arise initially in cervical region, [ $4^{\text {th }}$ week] increasing in number craniocaudally. In the $5^{\text {th }}$ week, the sclerotome cells of the somites lose their adherence and migrate to the vertebral centrum, neural process and costal processes. Each thoracic neural process gives rise to a cartilaginous pedicle, transverse process and lamina. The ossification centre arises, one for the centrum and one for the neural process, their timing is idiosyncratic starting in the $4^{\text {th }}$ month at T10 and L1 centra and C2 and T1 neural process and spreading up and down the column ${ }^{[8]}$. Radiologically, three types of vertebral fusion have been described, single fused cervical segment seen in $25 \%$ of patients multiple contiguous fused segments seen in $25 \%$ patients and multiple non -contiguous fused seen in $50 \%$ patients[9].

The segmentation of the vertebrae occurs at the time of organogenesis. The non segmentation of the primitive sclerotome is the causes for the fusion of vertebrae called block vertebrae or fused vertebrae. Congential fusion are characterised by absence of the intervertebral disc. Or its replacement by radio opaque line the wasp- waist appearance, smooth intervert ebralforamina, a single spinous process for two vertebral bodies and maintenance of vertebral body height on x-ray examination [10]. Block vertebrae results in disturbance in postural biomechancics causing degenerative changes and disc prolapsed at the adjoining segments in advance age [5]. Fusion between the typical thoracic vertebrae and lumbar vertebrae were reported by vadgaouear et al. which can cause low back pain [3]. early diagnosis of these anomalies will be helpful in documenting the change due to an injury, ageing or progression of a degenerative process and also motivates the patients to change their life styles to lead a normal life [7].

In the congenitally fused vertebrae, the anterioposterior diameter of the vertebrae is decreased and the individual measumerents of the two vertebraes bodies height is equal to the two fused vertebraes height including the inter-vertebral disc.

Vertebral synostosis is the hallmark of KFS, a traid of short neck mobility [1]. Acquired fusion of vertebrae may be subsequently shorting of the trunk. The thoracic vertebrae and the intervening disc along with ribs help in maintain the shape and length of the thorax.

Fusion of the vertebrae and the absence of the disc will narrow the thorax that can lead to respiratory distress. Asphyxiating thoracic dystrophy is caused by narrow thorax and short ribs [11, 12] congenital block vertebrae may be associated with other systematic anomalies that includes abnormal spinal curvatures scoliosis, etc, sprengels deformity, hemivertebrae, platybasia, basilar impression, spina bifida, clib feet, anomalies involving kidney and the ribs (cervical rib)cleft palate, respiratory problems, deafness or hearing impairment and cardiac anomalies $[6,13]$ various syndromes associations of vertebral fusion are segmentation syndrome with laryngeal malformations, VACTERL (s) (vertebral, Anal, Cardiovascular, 
Tracheo -oesophageal, renal and limb abnormalities), Mullerian duct aplasia, Renal aplasia, Cervico - thoracic somite dysplasia), diabetic embryopathy, trisomy 18, joubert, jarcho-levin syndrome, etc [14].

Pathological causes of fusion of vertebrae are fibro - dysplasia progressive juvenile rheumatoid arthritis etc [15]. The differentiation and resegmentation of vertebrae occurs at the time of organogenesis. It explains the association of vertebral synostosis with cardiac, renal, musculoskeletal and neural abnormalities [16].

\section{CONCLUSION}

Thoracic vertebral fusion usually results due to congenital or acquired causes and vertebral fusion can be helpful feature for identification. The study has provided additional information of the anatomy and morphology of thoracic vertebral fusion and their embryological basis and clinical significance. These details are clinically important as they might be associated with, neurological and musculoskeletal abnormalities.

\section{Conflicts of Interests: None}

\section{REFERENCES}

[1]. Erdil H, Yildiz N, Cimen M. Congenital fusionof cervical vertebrae and its clinicalsignificance. Journal of Anatomical Society ofIndia, 2003;52(2):125127.

[2]. Wazir S, Mahajan A. Fusion of axis with third cervical vertebra-a case report. Indian J Fundamental Applied Sciences, 2011;1(4):164-166.

[3]. Kulkarni V, Ramesh BR. A spectrum of vertebral synostosis. International Journal of Basic and Applied Medical Sciences, 2012;2(2):71-77.
[4]. Seaver LH, Boyd E. Spondyloc arpotar salsynost osis syndrome and cervical instability. PubmedAm J Med Genet, 2000;91(5):340-344.

[5]. Soni P, Sharma V, Sengupta J. Cervical vertebral anomalies- incidental findings on lateral cephalograms. The Angle Orthodontist, 2008;78(1):176-180.

[6]. Fernandes T, Costa C. Klippel-Feil syndrome with other associated anomaliesin a medieval Portugese skeleton (13th - 15th century). J Anat., 2007;211:681-685.

[7]. Shankar VV and Roopa R Kulkarni. Block vertebra, Fusion of axis with the third cervical vertebra- a case report. International Journal of Anatomical Variation, 2011;4:15-16.

[8]. Brookes M, Zietman A. Clinical Embryology. USA: Library of Congress; 1998: 293.

[9]. Johansen JG, mccartyDJ, Haughton VM . Retrosomatic clefts: computed tomographic appearance. Radiology, 1983; 148:447-448.

[10]. Brown M W, Templeton AW, Hodges F] III. The incidence of acquired and congenital fusion in the cervical spine. Am J Radiology, 1964;92:1255-1259.

[11]. Bhargava S. Radiological Differential Diagnosis. 1st edition, Jaypee Brothers, New Delhi, 2005:528.

[12]. Thomas D, Kulkarni BG. A case of fusion of thoracic vertebra. Journal of Ayurveda and Holistic Medicine, 2013;1(5):23-26.

[13]. Batra S, Ahuja S. Congenital Scoliosis: Management and future directions. ActaorthopedicaBelgica, 2008; 74:147-160.

[14]. Victor's Notes. Cranial and vertebral anomalies. Dev 9(1) updated by May 13, 2010.

[15]. Clarke RA, Catalan G, Diwan AD, Kearsley JH. Heterogeneity in Klippel-Feil syndrome: a new classification. Paediatric Radiology, 1998;28:967-974.

[16]. Kulkarni V, Ramesh BR. A spectrum of vertebral synostosis. International Journal of Basic and Applied Medical Sciences, 2012;2(2):71-77.

\section{How to cite this article:}

Nivedha Viswanathan, Ayesha Parveen, Yuvaraj Maria Francis, Priya Dharshini gowthaman. A. FUSION OF TYPICAL THORACIC VERTEBRAE: A CASE REPORT. Int J Anat Res 2017;5(2.3):39233926. DOI: 10.16965/ijar.2017.219 